\title{
Comparaison between Radial Forearm Free Flap (RFFF) and Anterolateral Thigh (ALT) Flap in Head and Neck Reconstruction
}

\author{
NOHA OSMAN A. MOHAMMED, M.Sc.; MOHAMMED A. HASANEIN, M.D.; \\ SAMIA M.A. SAIED, M.D. and AHMED G. ABDELMEGEED, M.D. \\ The Department of Plastic Surgery, Faculty of Medicine, Sohag University
}

\begin{abstract}
This is a prospective comparative study that aimed to compare two techniques for reconstruction of head and neck defects resulting from different causes in different ages, the radial forearm free flap (RFFF) and the anterolateral thigh flap (ALTF).
\end{abstract}

Setting: The Plastic Surgery Department of Sohag University Hospitals.

Patients and Methods: For this purpose, 18 patients with head and neck defects were recruited from the attendants of The Plastic Surgery Department, Sohag University Hospital during the period from January 2019 to January 2021 with head and neck defects of different causes and were divided into 2 groups; group A included 10 patients for whom anRFFF was done for reconstruction and group B (8 patients), for whom the free ALT flap was done to reconstruct their defects.

Results: The mean age for the whole group (mean $\pm \mathrm{SD}$ ) was $42.7 \pm 27$ years.

However, patients in group A were significantly older than those in group B $(59.1 \pm 18.5$ versus $22.5 \pm 20.9$ years respectively, $p<0.001)$. The commonest cause was excision of malignant tumors (10 cases) followed by traumatic defects (7 cases) and 1 case of Romberg's disease. The overall success rate was $72.2 \%$ (11 fully survived flaps and 1 case of peripheral necrosis) while 5 cases were lost to follow-up (27.8\%). The overall complication rate was $55.6 \%$ (10 cases): $70 \%$ (7 cases) in group A $37.5 \%$ ( 3 cases) in group B. The follow-up period ranged from 6 months to 1 year for both groups.

Conclusion: The RFFF is preferred in the elderly and the ALT in the younger age group with care of venous drainage either by a large caliber vein or double vein drainage.

Key Words: Radial forearm free flap - Anterolateral thigh flap - Head and neck.

Disclosure: No conflict of interest.

\section{INTRODUCTION}

Head and neck defects is a commonly faced problem occurring due to multiple cases affecting the soft tissue, bone or both in addition to the risk for affection of important structures like organs of special senses and aerodigestive tubes [1]. Free tissue transfer provided some advantages that put the choice to be a mainstay in head and neck reconstruction. These advantages that are possible to achieve due to the progression of the techniques of microvascular anastomosis and flap monitoring are centered on the ability to reconstruct medium and large sized defects in a single stage with the possibility of flap tailoring the flap for the best functional and aesthetic outcome in the least number of surgical procedures $[2,3]$. The ideal flap used for head and neck reconstruction should be versatile in design, of adequate tissue stock, of superior texture, with minimal donor site morbidity, has available multiple tissue types based on one pedicle, feasibility of two team approach and with consistent anatomy for easy and safe flap dissection [4].

Both Radial Forearm (RFFF) and Anterolateral thigh (ALT) free flaps have fulfilled most of these criteria and has been used for head and neck reconstruction with good results and acceptable rate of complications since first described by the Chinese in 1978 for the RFFF [5-7] and the 1990s for the ALT free flap $[4,7,8]$.

The details of RFFF harvest are found in the literature and are beyond mention in the current text [9]. The flap has the advantage of the long pedicle which makes it accessible for insetting in different regions. In addition, the thin flap, and availability to be folded makes it suitable for both coverage and lining to reconstruct both the outer surface and the mucosa of the oral and nasal cavities, in addition, the radial artery is not likely affected by atherosclerosis [5,10-14]. Yet, the flap has some disadvantages which include: A relatively small size and bulk, which makes it unsuitable for larger defects or defects requiring bulk, donor site scarring [5,6,10,15-21]. 
Anterolateral thigh flap (ALT) is a relatively recent workhorse for reconstruction that is used for tissue coverage and replacement in variable body parts. The anatomy of the flap and the technique of harvest is thoroughly discussed in literature $[\mathbf{7 , 8 , 2 2 - 2 5 ]}$. Due to the size of the flap that can reach $25 \times 35 \mathrm{~cm}$ the donor site is usually reconstructed by a split thickness graft. However, when the skin paddle is limited to 9 or $10 \mathrm{~cm}$ in width, the donor site can be closed primarily [7,23,26,27]. The flap was first described for head and neck reconstruction by Koshima et al., and Kimata et al., in late 1990s and 2000. Further reports have outlined the utility of this flap in head and neck reconstruction since it may be adapted to cover most defects of the face, neck, or intraoral regions $[\mathbf{2 3 , 2 4 , 2 7 ]}$. The flap may be thinned for pure intraoral defects. It also has good pliability and may be folded for the reconstruction of both the inner and outer lining of through and through defects [22,28].

While some authors stated the insignificant difference between the results of either flap in head and neck reconstruction $[\mathbf{1 4 , 2 9 ]}$, others stated the priority of the ALT flap over the RFFF for the lesser impact on donor site [28,30-32].

\section{PATIENTS AND METHODS}

The study included 18 patients randomly divided into two groups: Group A included 10 patients with head and neck defects that were reconstructed by RFFF, and group B included 8 patients with head and neck defects that were reconstructed by free ALT flap.

Pre-operative evaluation was done with detailed history taking including age, smoking and history of previous operation and available surgical and histopathological reports in cases of recurrent malignancy, and thorough physical examination.

Surgical techniques of flap harvesting followed the described in literature for both groups [7,9]. The microvascular anastomosis was done using 9/0 Ethilon ${ }^{\circledR}$ sutures; meanwhile, a bolus of intravenous heparin is given. The donor sites were closed either primarily or by a split thickness skin graft according to the size of the defect. For both groups two teams' approach is to be adopted to minimize the operative time and blood loss.

Post-operative care was in the form of light dressing with a window for flap monitoring in terms of color, temperature, and capillary refill, blood volume expansion by administration of Voluven ${ }^{\circledR}$ solution with monitoring of the general condition of the patient as regards heart rate, blood pressure and urinary output, and administration of Pentoxyfylline (Trental) $400 \mathrm{mg}$ twice daily for adult patients and $200 \mathrm{mg}$ twice daily for children, and Cilostazol (Pletal) $50 \mathrm{mg}$ twice daily for adult patients and $25 \mathrm{mg}$ twice daily for children in addition to intravenous broad-spectrum antibiotic for at least 7 days, and good analgesia. Flap monitoring was performed every 30 minutes in the $1^{\text {st }}$ 12 post-operative hours, then hourly for the following 48 hours, and every 2 hours in the following 72 hours. Follow-up for 3-12 months after surgery, for functional and aesthetic outcomes.

Tabulation of the obtained results was done for comparison as regards flap survival (total and partial), donor site morbidity, patient satisfaction and cost in terms of operative time and hospital stay. Statistical analysis was done via the Statistical Package for the Social Sciences (SPSS) through applying student $t$-test and chi-square test to compare the variables in the two groups.

\section{RESULTS}

The study included 18 patients whose ages ranged from 3 to 85 years with a mean age of 42.4 \pm 27 years and sex distribution was 10 males $(55.5 \%)$ and 8 females $(44.5 \%)$. Defect size ranged from 15 to $130 \mathrm{~cm}^{2}$ with a mean size of $52.6 \pm 32.2$ $\mathrm{cm}^{2}$.

Complete flap survival occurred in 12 cases $(66.7 \%)$, partial loss occurred in 1 case $(5.5 \%)$ and total loss of 5 (27.8\%) (Tables 1,2, Figs. 1,2).

Table (1): Patient's demographic data.

\begin{tabular}{|c|c|c|c|}
\hline & Group A & Group B & $\begin{array}{c}\text { Overall } \\
\text { mean or total }\end{array}$ \\
\hline Patient number & 10 & 8 & 18 \\
\hline $\begin{array}{l}\text { Age (years) } \\
p=0.001\end{array}$ & $59.1 \pm 18.5$ & $21.5 \pm 20.9$ & $42.4 \pm 27$ \\
\hline $\begin{array}{l}\text { Gender } \\
\text { (percentage) }\end{array}$ & $\begin{array}{l}\text { Males: } 80 \% \\
\text { Females: } 20 \%\end{array}$ & $\begin{array}{l}\text { Males: } 25 \% \\
\text { Females: } 75 \%\end{array}$ & $\begin{array}{l}\text { Males: } 55.6 \% \\
\text { Females: } 44.4 \%\end{array}$ \\
\hline $\begin{array}{l}\text { Defect size }\left(\mathrm{cm}^{2}\right) \\
p=0.47\end{array}$ & $47.5 \pm 28.6$ & $59 \pm 37.2$ & $52.6 \pm 32.2$ \\
\hline $\begin{array}{l}\text { Smokers } \\
\text { (percentage) }\end{array}$ & $\begin{array}{l}\text { Smokers: } \\
50 \% \text { ( } 5 \text { cases) } \\
\text { Non-smokers: } \\
50 \% \text { ( } 5 \text { cases) }\end{array}$ & $\begin{array}{l}\text { Smokers: } \\
12.5 \% \text { ( } 1 \text { case) } \\
\text { Non-smokers: } \\
87.5 \% \text { ( } 7 \text { cases) }\end{array}$ & $\begin{array}{l}\text { Smokers: } \\
33.3 \% \text { ( } 6 \text { cases }) \\
\text { Non-smokers: } \\
66.7 \% \text { ( } 12 \text { cases) }\end{array}$ \\
\hline
\end{tabular}


Table (2): Compared outcomes of both groups.

\begin{tabular}{|c|c|c|c|}
\hline & Group A & Group B & $\begin{array}{c}\text { Overall } \\
\text { mean or total }\end{array}$ \\
\hline $\begin{array}{l}\text { Ischemia time } \\
\text { in minutes } \\
p=0.01\end{array}$ & $65 \pm 11.8$ & $100 \pm 36.7$ & $80.6 \pm 30.8$ \\
\hline $\begin{array}{l}\text { Operative time } \\
\text { in hours } \\
p=0.26\end{array}$ & $3.3 \pm 0.36$ & $3.5 \pm 0.5$ & $3.4 \pm 0.4$ \\
\hline $\begin{array}{l}\text { Pedicle length } \\
\text { in } \mathrm{mm} \\
p=0.07\end{array}$ & $63.5 \pm 8.2$ & $70 \pm 5.3$ & $66.4 \pm 7.6$ \\
\hline $\begin{array}{l}\text { Hospital stay } \\
\text { in days } \\
p=0.15\end{array}$ & $15.9 \pm 6.8$ & $11.9 \pm 3.6$ & $14.11 \pm 5.8$ \\
\hline $\begin{array}{r}\text { Total flap loss } \\
\text { (percentage) }\end{array}$ & $20 \%$ (2 cases) & $37.5 \%$ ( 3 cases $)$ & $27.8 \%$ (5 cases) \\
\hline $\begin{array}{l}\text { Overall flap } \\
\text { complications } \\
\text { (percentage) }\end{array}$ & $70 \%$ (7 cases) & $37.5 \%$ ( 3 cases $)$ & $55.6 \%$ (10 cases) \\
\hline $\begin{array}{l}\text { Secondary } \\
\text { procedure } \\
\text { (percentage) }\end{array}$ & $60 \%$ (6 cases $)$ & $50 \%$ (4 cases) & $61.1 \%(11$ cases $)$ \\
\hline
\end{tabular}

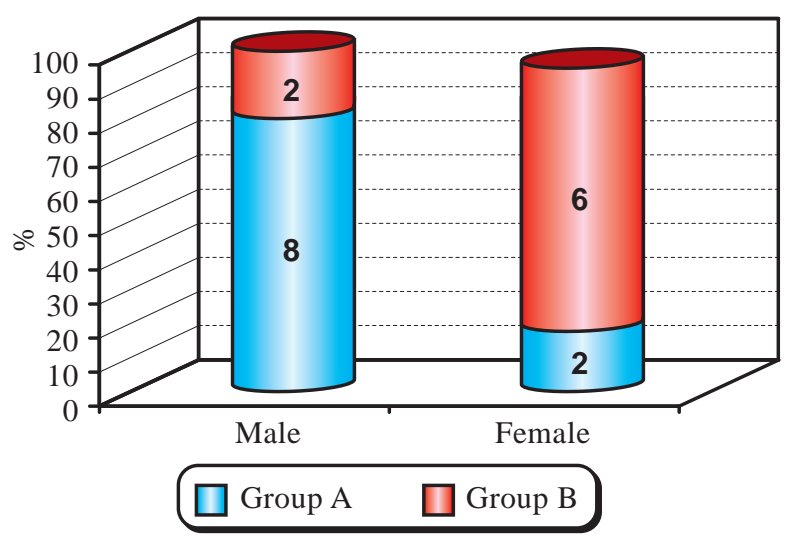

Fig. (1): Overall gender distribution.

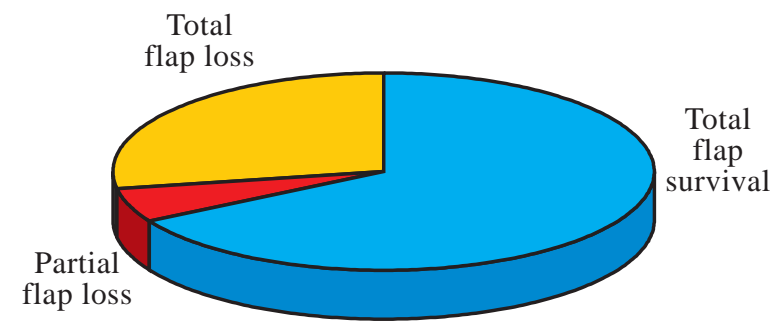

Fig. (2): Overall flap outcome.

For Group A, ages ranged from 18 to 85 years oldwhere 7 were males and 3 females. Defect size ranged from 15 to $96 \mathrm{~cm}^{2}$ caused by malignant tumor excision ( 8 cases) or trauma ( 2 cases) and sites were the forehead ( 2 cases), orbital region (1 case), cheek and nose (2 cases), oral commissure ( 2 cases) and lower lip (3 cases) (Table 3, Figs. $3,4)$. Reconstruction was performed either immediately in cases where tumor resection was done at the same sitting of reconstruction ( 8 cases) or after 5-7 days after the incidence of the traumatic defect. Total flap survival occurred in 7 cases, 1 flap was partially lost and 2 flaps were totally lost. Pedicle length ranged from 45 to $75 \mathrm{~mm}$. Ischemia time ranged from 45 to 90 minutes. Arterial anastomosis was done end to end to the facial artery in 7 cases and the superficial temporal artery in 3 cases. Venous anastomosis was done end to end to the facial vein in 7 cases and the superficial temporal vein in 3 cases. All flaps were drained by a single vein. Operative time ranged from 3 to 4 hours.

Table (3): Site predilection of each group.

\begin{tabular}{lccc}
\hline & Group A & Group B & Total \\
\hline Forehead & 2 & 5 & 7 \\
Orbital & 1 & - & 1 \\
Oral commissure & 2 & - & 2 \\
Cheek & 2 & 2 & 4 \\
Lip & 3 & - & 3 \\
Temporal & - & 1 & 1 \\
\hline Total & 10 & 8 & 18 \\
\hline
\end{tabular}

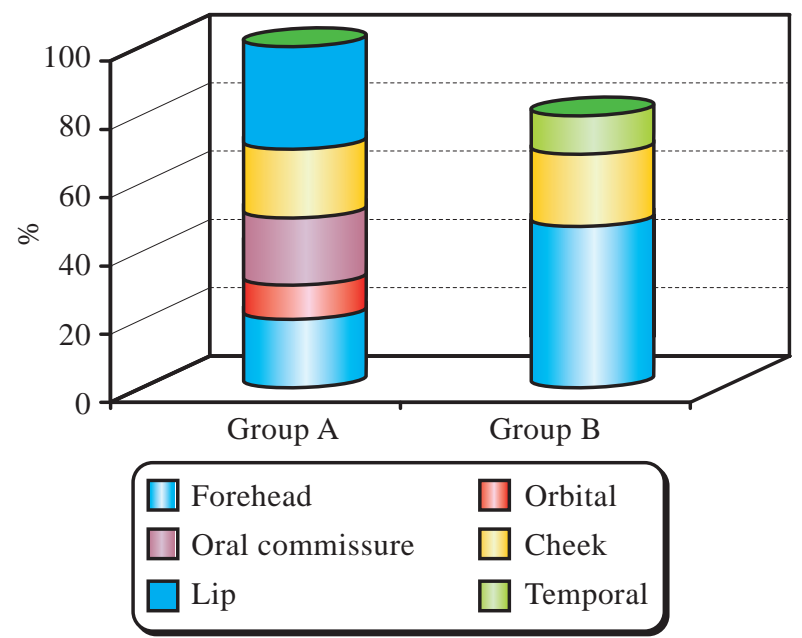

Fig. (3): Site predilection on each group.

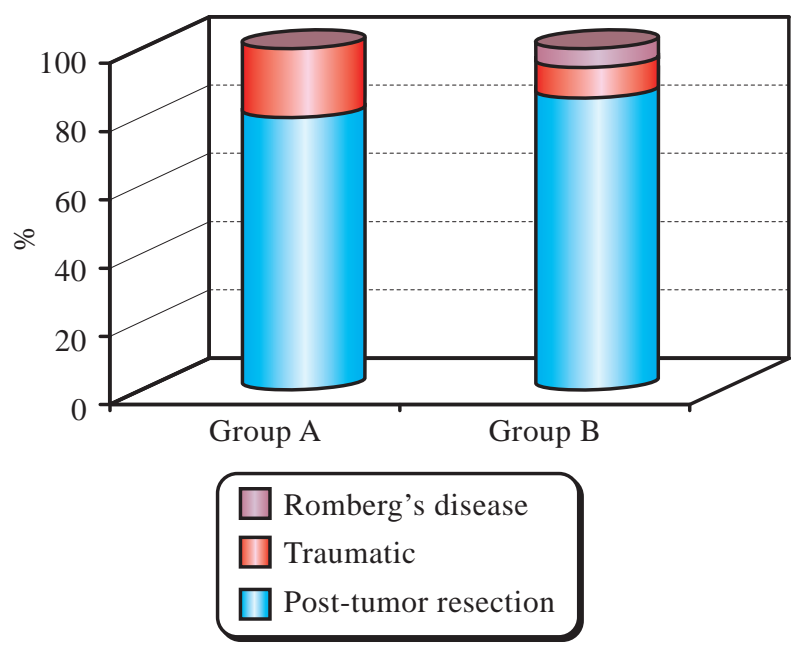

Fig. (4): Aetiology of defect in each group. 
Total ischemias occurred in 2 cases, both were in the lower lip, partial ischemia occurred in 1 case, where debridement was done for the ischemic parts and reconstruction was done by advancement of local tissue. Oedema and mild infection occurred in 2 cases that were managed conservatively while in 2 cases there was significant oedema with an underlying hematoma that was evacuated and the flaps were salvaged (Table 4).

Table (4): Complications of each group.

\begin{tabular}{lcc} 
& Group A & Group B \\
\hline Oedema and infection & 2 & - \\
Hematoma & 2 & - \\
Total flap loss & 2 & 3 \\
Partial flap loss & 1 & - \\
\hline
\end{tabular}

Debulking was needed in 2 cases with commissuroplasty that was done 6 months after the primary reconstruction.

All patients were right-handed. The donor forearm was on the right side in 6 cases back to a left sided defect obstructing the harvesting team from proceeding simultaneously with the recipient preparing team, and on the left side in 4 cases. The donor site needed a split thickness skin graft in all cases that were smoothly taken, and the result was satisfactory in all patients with no reported complications either functional deficits or cosmetic.

The hospital stay ranged from 7 to 25 days, and the follow-up ranged from 6 moths to one year.

\section{Case presentation:}

1- Case No. (1): Female patient 18 years old, presented to the emergency ward with a traumatic raw area in the left side of the forehead with exposed skull bones as a result of a road traffic accident. She had a RFFF reconstruction (Fig. 5). The donner site was reconstructed by a split thickness skin graft that was fully taken (Fig. 6).
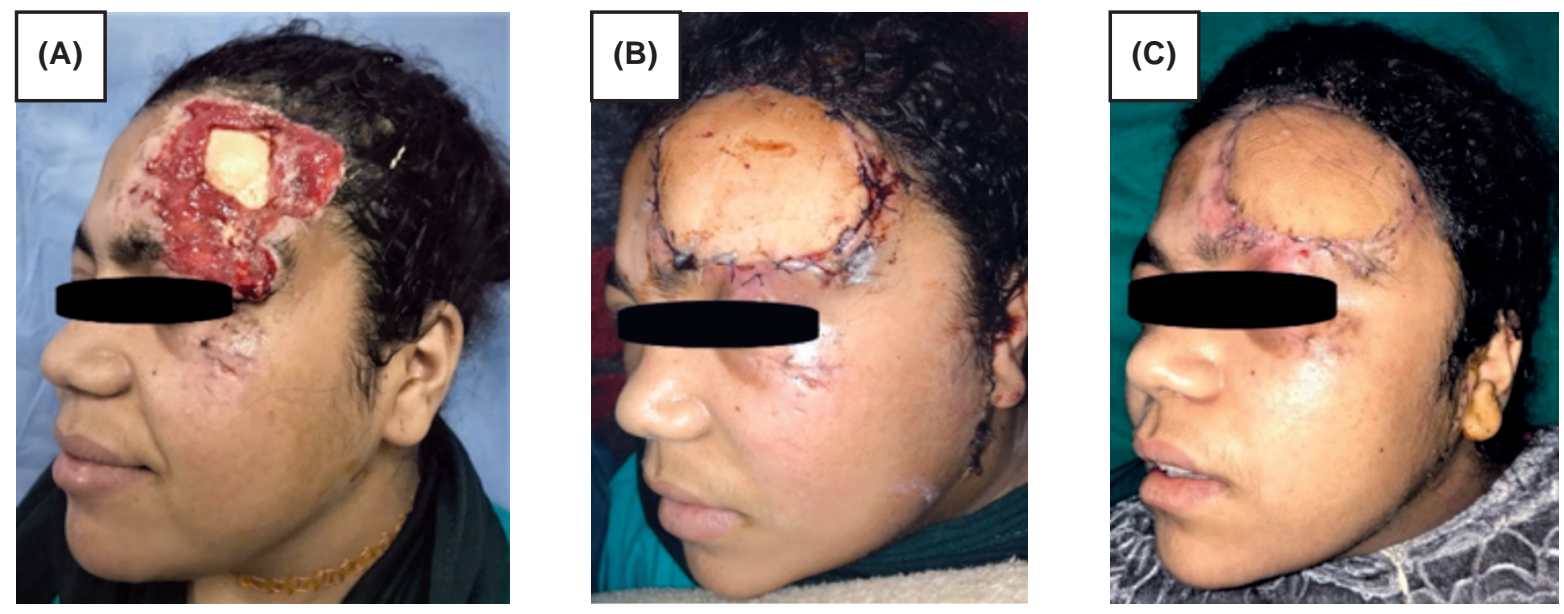

Fig. (5): Case 1 [RFFF] (A): Pre-operative photo showing a post-traumatic defect of the forehead with exposed skull bones. (B) 2 days post-operative. (C) 1 month post-operative.

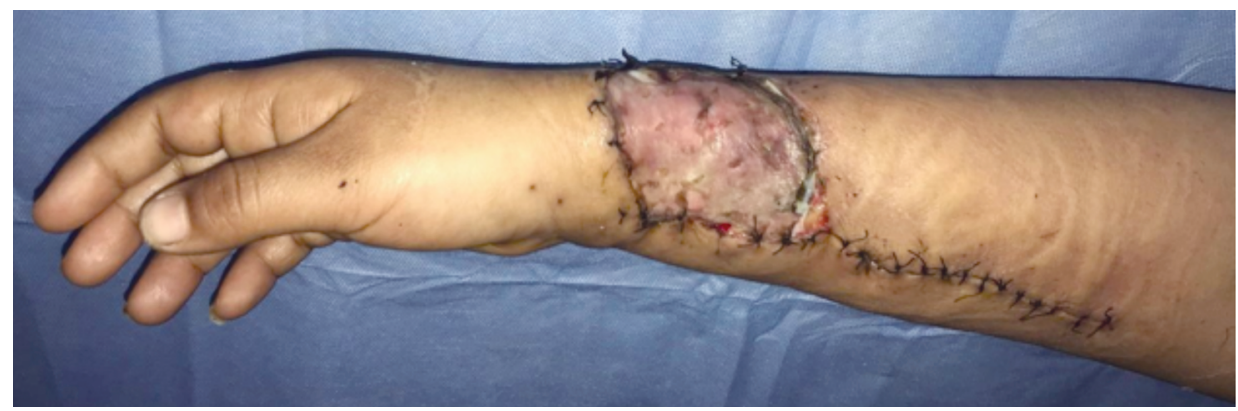

Fig. (6): Donor site, closure done by a split thickness skin graft.

For group B, ages ranged from 3 to 63 years, where 2 were males and 6 females. Defect size ranged from 20 to $130 \mathrm{~cm}^{2}$ caused by malignant tumor excision ( 2 cases), trauma (5 cases), or adult hemifacial atrophy (Romberg's disease) in 1 case, and sites were the forehead (5 cases), temporal region ( 1 case), and cheek ( 2 cases) (Table 3, Figs. $3,4)$. Reconstruction was performed either immediately in cases where tumor resection was done at the same sitting of reconstruction ( 2 cases) or after 2-7 days after the incidence of the traumatic and developmental defect (5 cases). Total flap 
survival occurred in 5 cases, and 3 flaps were totally lost. Pedicle length ranged from 65 to $75 \mathrm{~mm}$. Ischemia time ranged from 50 to 170 minutes. Arterial anastomosis was done end to end to the facial artery in 3 cases and the superficial temporal artery in 5 cases. Venous anastomosis was done end to end to the external jugular vein in 3 cases and the superficial temporal vein in 5 cases. All flaps were drained by a single vein. Operative time ranged from 3 to 4.5 hours. Total ischemia occurred in 3 cases all were in the forehead where debridement was done, and reconstruction was performed by rotational or advancement flaps (Table 4). Debulking was needed in 1 case of an adipofascial flap that was done 6 months after the primary reconstruction.

The donor site needed a split thickness skin graft in 2 cases that were smoothly taken, and primary closure in 6 cases with a satisfactory result in all patients with no reported complications.

The hospital stay ranged from 10 to 20 days, and the follow-up ranged from 6 to 9 months.

2- Case No. (2): Male patient 65 years old, presented to Sohag Plastic Surgery Department with a malignant tumor (SCC) affecting the left oral commissure extending intraorally. Tumor excision was done, and reconstruction was done by a RFFF. Six months later, debulking was done (Fig. 7).
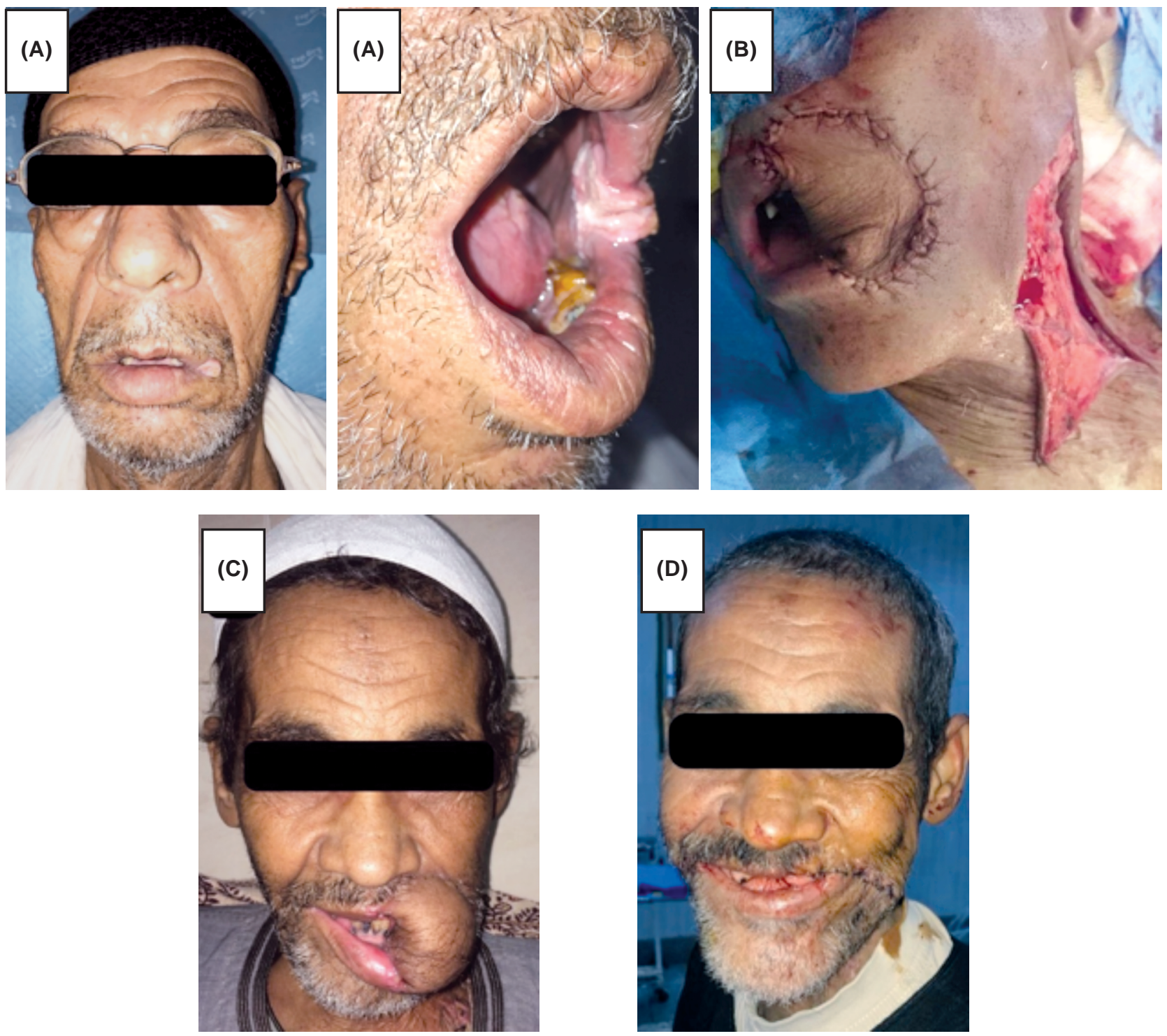

Fig. (7): Case 3 [RFFF]: (A) Pre-operative photos showing an ulcerative malignant mass affecting the left oral commissure (left) with extension inside oral mucosa (right). (B) Intra-operative photo for the flap after inset where most of the flap is intra-oral for the mucosal defect. (C) Post-operative photo showing the flap before debulking and commissuroplasty. (D) After debulking and commissuroplasty. 
3- Case No. (3): Male patient 75 years old, presented to Sohag Plastic Surgery Department with a malignant tumor (SCC) affecting the lower lip. Tumor excision was done, and reconstruction was done using a RFFF. The flap was lost and debridement was done, followed by reconstruction with Karpandazic flap (Fig. 8).
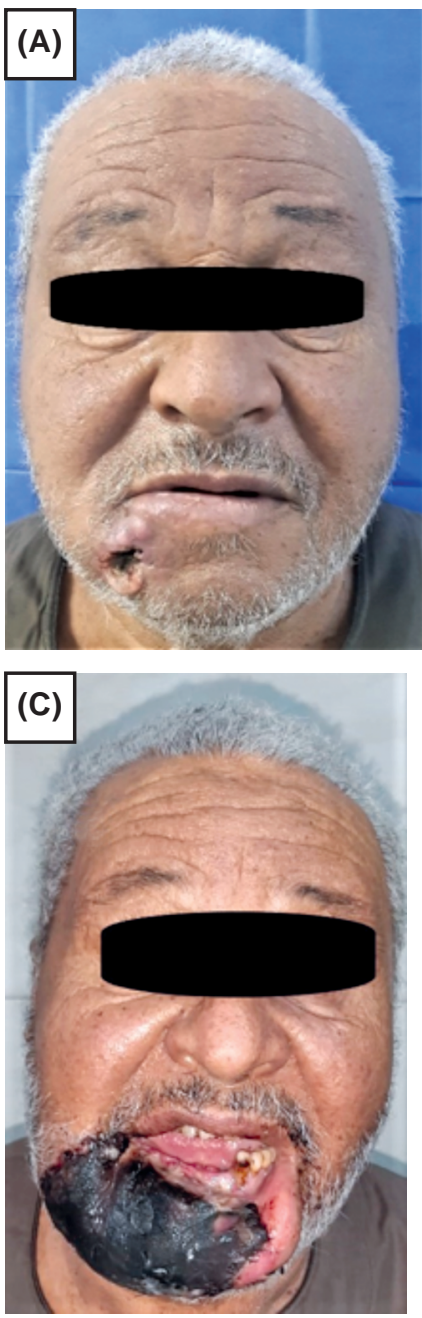
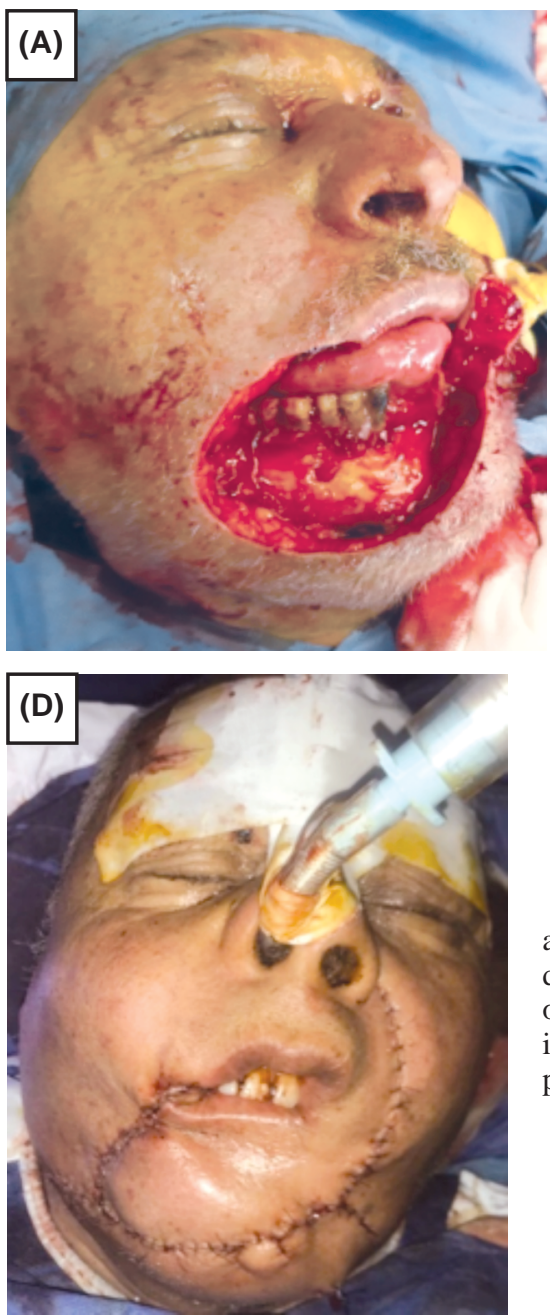

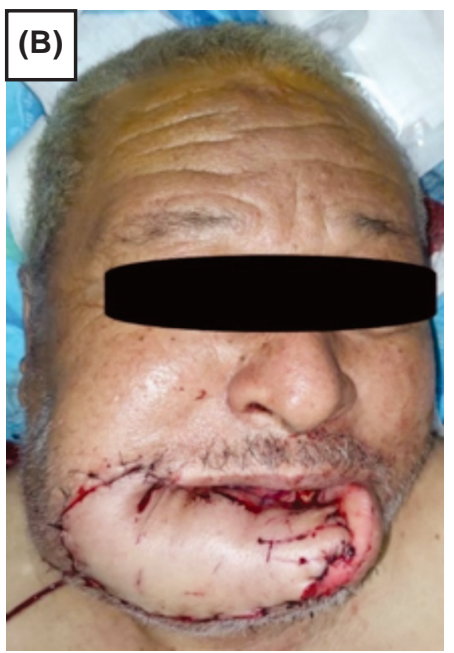

Fig. (8): Case 4 [RFFF]: (A) Pre-operative and defect size after tumor excision. (B) 2 days post-operative. (C) 1 week postoperative. (D) After debridement of the ischemic flap and reconstruction with Karpandazic flap.
4- Case No. (4): Male patient, 42 years old, presented to Sohag Plastic Surgery Department with a malignant tumor (SCC) affecting the right cheek. Excision with safety margin was done, and reconstruction of the defect was done using an ALT flap (Fig. 9).
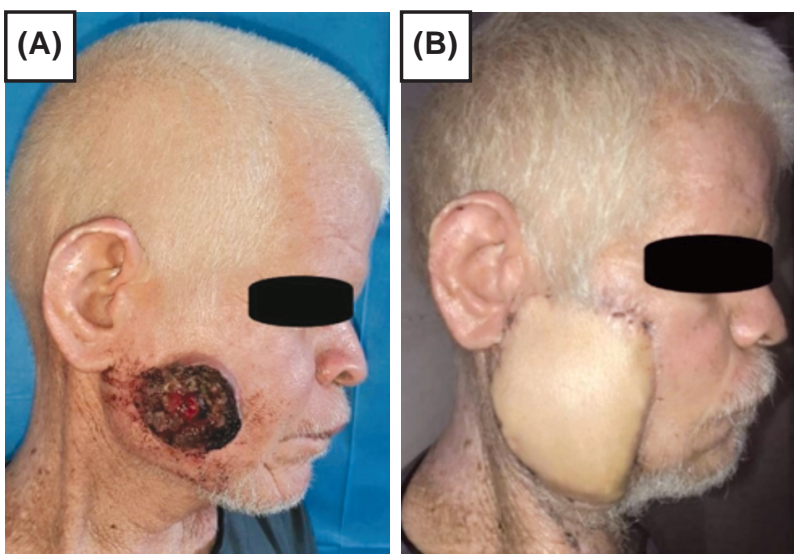

Fig. (9): Case 5 [ALT]: (A) Pre-operative photo showing malignant ulcer occupying the right cheek. (B) Postoperative.
5- Case No. (5): Female patient, 3 years old, presented to the emergency ward with a traumatic raw area in the left side of the forehead with exposed skull bones as a result of a road traffic accident. Reconstruction was done using an ALT flap (Fig. 10).

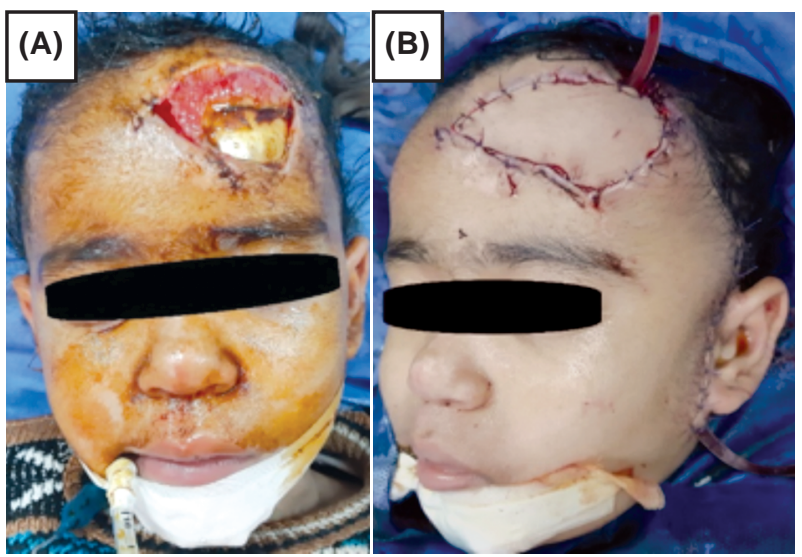

Fig. (10): Case 6 [ALT]: (A) Pre-operative photo showing a post-traumatic defect of the forehead with exposed skull bones. (B) Post-operative. 


\section{DISCUSSION}

Head and neck defects represent a common problem raising mainly from excision of malignancies and road traffic accidents, being an exposed area and as an important aesthetic issue during reconstructing the defect to achieve the best functional and aesthetic outcome.

Free tissue transfer is widely becoming a first choice for reconstruction of medium and large sized defects including those of the head and neck. Various flap types are used for this purpose with the RFFF and ALT flap being workhorse flaps due to ease of dissection, large size of tissue available for transfer and relatively constant anatomy.

The current study aimed at comparing these two types of flaps amongst a sample of patients with such a problem in an upper Egyptian community and to compare the experience in Sohag University Hospitals with what is available in the world literature in this respect in terms of flap versatility operative time, hospitalization time, early and late complications, donor site morbidity and cosmetic outcome.

The decision was modified intra-operatively for 2 cases planned for joining group B due to failure to identify a dependable perforator, thus were excluded from the study. This was mentioned in the work of Lakhiani et al. and Lim et al., as well as Valentini et al., who reported absence of cutaneous perforators for ALT in 2 patients [32-34].

The goal of reconstruction in cases presented with malignancy was to fully excise the malignant tissue and fill the defect with a flap that is most likely suitable for restoring the target functional and aesthetic result, putting in consideration the higher age with the least operative risks. On the other hand, for the traumatic defects, the aim was to cover the defect and underlying bones with a matching non-bulky flap that is less likely to need further interference, so that the functional and aesthetic result would be satisfactory to the patient.

Both the RFFF and free ALT were used successfully for reconstruction of variable head and neck defects since decades with high rates of fully survived flaps not less than $90 \%[\mathbf{1 4 , 2 5 , 2 7 , 3 1 , 3 2 ]}$. However, the overall success rate in the current study was $72.2 \%$; for group A it was $80 \%$ and $62.5 \%$ for group B. This can be explained by the fact that in all lost flaps (5 cases representing $27.8 \%$ ) venous congestion was not detected before skin changes were eminent which was by the third post-operative day in 3 cases and on the fourth day in 2 cases, hence, no re-exploration was done. Occurrence of congestion that led to flap loss may encourage to consider the performance of a semifree radial forearm flap that is supposed to overcome this problem as stated by Quilichini et al., in 2012 [35] if a second recipient vein could not be obtained.

For Group B, the 3 lost cases were for females 3,5 and 6 years old, all with traumatic defects of the scalp and had their flaps drained with a single vein that was the superficial temporal vein. One of these cases had an ischemia time of almost 3 hours for faulty anastomosis of the arteries to the veins that required re-anastomosis.

Single vein drainage was efficiently sufficient for the remaining patients of both groups with different named veins: Superficial temporal, facial and external jugular. Single vein pedicle was due to inability to find another vein with suitable length and caliber in the recipient field to which another vein could be connected with no tension.

The ischemia time was significantly $(p=0.01)$ longer in group B $(100 \pm 36.7$ minutes) than in group A $(65 \pm 11.8$ minutes). This can be explained by the highly significant $(p=0.001)$ younger age in group B (21.5 \pm 20.9 years) that included 3 patients 6year-old and younger who had small caliber vessels more difficult for anastomosis.

Hospitalization time, operative time and pedicle length were comparable in both groups.

Patients in the current study were satisfied with the donor site in both groups. There were no reported donor site complications although what is found in literature states that there is a higher rate for radial forearm donor complications functionally and aesthetically which included hand numbness, motor disability in the form of inability to lift heavy objects cold intolerance and the unsightly scar $[19,32,36]$. Although similar results to the current study were found in literature [37-39], from the perspective of a plastic surgeon, the donor site of the ALT is preferable being of a less functional risk, and rather hidden for more cosmetic satisfaction.

When it comes to lower lip reconstruction, the RFFF stands as an optimum first choice for free tissue transfer, for the possibility of harvesting a narrow flap with an opportunity of direct closure of the donor site [40] and for the easier manipulation for respecting this aesthetic unit of the face as shown by Sadove et al., in 1991 [41]. In this study, the best results were obtained in reconstruction of the oral commissure with the RFFF. 


\section{Conclusion:}

Free flaps are coming in advance for choices in reconstruction of head and neck defects of various reasons. Most of these defects are of large sizes and are due to trauma or more often a wide excision of a malignant tumor, which makes it hard to reconstruct using local tissues with minimal affection of cosmesis.

The radial forearm free flap (RFFF) was considered the perfect choice for free tissue transfer to the head and neck until the introduction of the free anterolateral thigh (ALT) flap as an alternative. Both flaps have their advantages over each other, but the most evident is the advantage of the ALT over the RFFF as regards the donor site and the relatively consistent anatomy.

Thus, regarding this study, it is recommended that both flaps are competent in the context of head and neck reconstruction, with the preference of the RFFF in the elderly and the ALT in the younger age group with care of venous drainage either by double vein drainage or connecting the flap vein to a large caliber vein like the external jugular for sufficient drainage.

It is also recommended to pay attention to the training of the team, specially as regards the flap monitoring, to make it possible to save congested flaps in the proper time. Lastly, it is recommended to conduct the study on a bigger number of patients, for more informative and conclusive results.

\section{REFERENCES}

1- Gerressen M., Pastaschek C.I., Riediger D., Hilgers RD., Hölzle F., Noroozi N., et al.: Microsurgical free flap reconstructions of head and neck region in 406 cases: A 13-year experience. Journal of Oral and Maxillofacial Surgery, 71 (3): 628-35, 2013.

2- Markey J., Knott P.D., Fritz M.A. and Seth R.: Recent advances in head and neck free tissue transfer. Curr. Opin. Otolaryngol. Head Neck Surg., 23 (4): 297-301, 2015.

3- van Gijn D.R., D'Souza J., King W. and Bater M.: Free Flap Head and Neck Reconstruction with an Emphasis on Post-operative Care. Facial Plast. Surg., 34 (6): 597 604, 2018.

4- Demirkan F., Chen H-C., Wei F-C., Chen H-H., Jung SG., Hau S-P., et al.: The versatile anterolateral thigh flap: a musculocutaneous flap in disguise in head and neck reconstruction. British Journal of Plastic Surgery, 53 (1): 30-6, 2000.

5- Evans G.R., Schusterman M.A., Kroll S.S., Miller M.J., Reece G.P., Robb G.L., et al.: The radial forearm free flap for head and neck reconstruction: A review. The American Journal of Surgery, 168 (5): 446-50, 1994.

6- Guofan Y., Baoqui C. and Yuzhi G.: Forearm free skin flap transplantation. National Medical Journal of China, 61: 139, 1981.
7- Song Y-G., Chen G-Z. and Song Y-L.: The free thigh flap: A new free flap concept based on the septocutaneous artery. British Journal of Plastic Surgery, 37 (2): 149-59, 1984.

8- Wong C.H. and Wei F.C.: Anterolateral thigh flap. Head Neck, 32 (4): 529-40, 2010.

9- Muhlbauer W., Herndl E. and Stock W.: The forearm flap. Plast. Reconstr. Surg., 70 (3): 336-44, 1982.

10- Ahmad F.I., Means C., Labby A.B., Troob S.H., Gonzalez J.D., Kim M.M., et al.: Osteocutaneous radial forearm free flap in nonmandible head and neck reconstruction. Head Neck, 39 (9): 1888-93, 2017.

11- Chen H., Ganos D.L., Coessens B.C., Kyutoku S. and Noordhoff M.S.: Free forearm flap for closure of difficult oronasal fistulas in cleft palate patients. Plastic and Reconstructive Surgery, 90 (5): 757-62, 1992.

12- Dewey E.H., Roche A.M., Lazarus C.L. and Urken M.L.: Total lower lip and chin reconstruction with radial forearm free flap: A novel approach. Am. J. Otolaryngol., 38 (5): 618-25, 2017.

13- Hentz V.R., Pearl R.M., Grossman J.A., Wood M.B. and Cooney W.P.: The radial forearm flap: A versatile source of composite tissue. Ann. Plast. Surg., 19 (6): 485-98, 1987.

14- Oranges C.M., Ling B., Tremp M., Wettstein R., Kalbermatten D.F. and Schaefer D.J.: Comparison of anterolateral thigh and radial forearm free flaps in head and neck reconstruction. In vivo., 32 (4): 893-7, 2018.

15- Ahmed T.I. and Ismail A.: The free fascial forearm flap. Microsurgery, 10 (3): 155-60, 1989.

16- Chen H.C., Ganos D.L., Coessens B.C., Kyutoku S. and Noordhoff M.S.: Free forearm flap for closure of difficult oronasal fistulas in cleft palate patients. Plast. Reconstr. Surg., 90 (5): 757-62, 1992.

17- Fenton O.M. and Roberts J.O.: Improving the donor site of the radial forearm flap. Br. J. Plast. Surg., 38 (4): 5045,1985 .

18- Harii K., Ebihara S., Ono I., Saito H., Terui S. and Takato T.: Pharyngoesophageal reconstruction using a fabricated forearm free flap. Plastic and Reconstructive Surgery, 75 (4): 463-76, 1985.

19- Jani K., Maharaja N., Akali N.R., Balasubramanian D., Ramu J., Mathew J., et al.: Long-Term Patient-Reported Outcomes of Radial Forearm Free Flap Donor Site in the Context of Head and Neck Cancer Reconstruction. Indian Journal of Surgical Oncology, 1-4, 2019.

20- Safak T. and Akyürek M.: Free transfer of the radial forearm flap with preservation of the radial artery. Annals of Plastic Surgery, 45 (1): 97-9, 2000.

21- Timmons M., Missotten F., Poole M. and Davies D.: Complications of radial forearm flap donor sites. British Journal of Plastic Surgery, 39 (2): 176-8, 1986.

22- Chana J.S. and Wei F.C.: A review of the advantages of the anterolateral thigh flap in head and neck reconstruction. Br. J. Plast. Surg., 57 (7): 603-9, 2004.

23- Koshima I.: Free Anterolateral Thigh Flap for Reconstruction of Head and Neck Defects following Cancer Ablation by Shyh-Jou Shieh, MD, Haw-Yen Chiu, MD, Jui-Chin Yu, MD, Shin-Chen Pan, MD, Sen-Tien Tsai, MD, and 
Ching-Liang Shen, Ph. D. Plastic and reconstructive surgery, 105 (7): 2358-60, 2000.

24- Koshima I., Fukuda H., Yamamoto H., Moriguchi T., Soeda S. and Ohta S.: Free anterolateral thigh flaps for reconstruction of head and neck defects. Plastic and Reconstructive Surgery, 92 (3): 421-8; discussion 9-30, 1993.

25- Wolff K-D., Kesting M., Thurmüller P., Böckmann R. and Hölzle F.: The anterolateral thigh as a universal donor site for soft tissue reconstruction in maxillofacial surgery. Journal of Cranio-Maxillofacial Surgery, 34 (6): 323-31, 2006.

26- Chen C-M., Chen C-H., Lai C-S., Lin S-D., Huang I-Y. and Shieh T-Y.: Anterolateral thigh flaps for reconstruction of head and neck defects. Journal of Oral and Maxillofacial Surgery, 63 (7): 948-52, 2005.

27- Kimata Y., Uchiyama K., Ebihara S., Yoshizumi T., Asai M., Saikawa M., et al.: Versatility of the free anterolateral thigh flap for reconstruction of head and neck defects. Archives of Otolaryngology-Head \& Neck Surgery, 123 (12): 1325-31, 1997.

28- Farace F., Fois V.E., Manconi A., Puddu A., Stomeo F., Tullio A., et al.: Free anterolateral thigh flap versus free forearm flap: Functional results in oral reconstruction. J. Plast. Reconstr. Aesthet Surg., 60 (6): 583-7, 2007.

29- Li W., Xu Z., Liu F., Huang S., Dai W. and Sun C.: Vascularized free forearm flap versus free anterolateral thigh perforator flaps for reconstruction in patients with head and neck cancer: Assessment of quality of life. Head Neck, 35 (12): 1808-13, 2013.

30- Knott P.D., Seth R., Waters H.H., Revenaugh P.C., Alam D., Scharpf J., et al.: Short-term donor site morbidity: A comparison of the anterolateral thigh and radial forearm fasciocutaneous free flaps. Head Neck, 38 (Suppl 1): E945-8, 2016.

31- Liu W.W., Li H., Guo Z.M., Zhang Q., Yang A.K., Liu X.K., et al.: Reconstruction of soft-tissue defects of the head and neck: Radial forearm flap or anterolateral thigh flap? Eur. Arch. Otorhinolaryngol., 268 (12): 1809-12, 2011.

32- Valentini V., Cassoni A., Marianetti T.M., Battisti A., Terenzi V. and Iannetti G.: Anterolateral thigh flap for the reconstruction of head and neck defects: Alternative or replacement of the radial forearm flap? Journal of Craniofacial Surgery, 19 (4): 1148-53, 2008.

33- Lakhiani C., Lee M.R. and Saint-Cyr M.: Vascular anatomy of the anterolateral thigh flap: A systematic review. Plastic and Reconstructive Surgery, 130 (6): 1254-68, 2012.

34- Lim S., Atwi N., Long S., Toshav A. and Lau F.H.: Variations in the anterolateral thigh flap's vascular anatomy in African Americans. Journal of reconstructive microsurgery, 34 (04): 300-6, 2018.

35- Quilichini J., Benjoar M.D., Hivelin M., Brugel L. and Lantieri L.: Semi-free radial forearm flap for head and neck reconstruction in vessel-depleted neck after radiotherapy or radical neck dissection. Microsurgery, 32 (4): 269-74, 2012.

36- De Witt C.A., De Bree R., Verdonck-de Leeuw I.M., Quak J.J. and Leemans C.R.: Donor site morbidity of the fasciocutaneous radial forearm flap: What does the patient really bother? European archives of oto-rhino-laryngology, 264 (8): 929-34, 2007.

37- Chang S.C.N., Miller G., Halbert C.F., Yang K.H., Chao W.C. and Wei F.C.: Limiting donor site morbidity by suprafascial dissection of the radial forearm flap. Microsurgery: Official Journal of the International Microsurgical Society and the European Federation of Societies for Microsurgery, 17 (3): 136-40, 1996.

38- Lutz B.S., Wei F-C., Chang SC., Yang K-H. and Chen IH.: Donor site morbidity after suprafascial elevation of the radial forearm flap: A prospective study in 95 consecutive cases. Plastic and Reconstructive Surgery, 103 (1): 132-7, 1999.

39- Novak C.B., Lipa J.E., Noria S., Allison K., Neligan P.C. and Gilbert R.W.: Comparison of anterolateral thigh and radial forearm free flap donor site morbidity. Microsurgery: Official Journal of the International Microsurgical Society and the European Federation of Societies for Microsurgery, 27 (8): 651-4, 2007.

40- Zhang Y.X., Xi W., Lazzeri D., Zhou X., Li Z., Nicoli F., et al.: Bipaddle radial forearm flap for head and neck reconstruction. Journal of Craniofacial Surgery, 26 (2): 350-3, 2015.

41- Sadove R.C., Luce E.A. and McGrath P.C.: Reconstruction of the lower lip and chin with the composite radial forearmpalmaris longus free flap. Plastic and Reconstructive Surgery, 88 (2): 209-14, 1991. 